\title{
Automotive Customer Service Evaluation Based on BP Neural Network
}

\author{
Juan LIU \\ Shangdong Women's University, Ji'nan, China
}

Jichen Fang

Weichai Holdings Group Co., Ltd, Weifang, China

\begin{abstract}
It is very important to evaluate the automotive customer service for people, but do not have a unified standard to it. Through the research of BP network, we established automotive service satisfaction evaluation model based on BP neural network. Then, evaluated the performance of service satisfaction in the area where the object of 14 service stations in the fourth quarter 2013, analysed the evaluation examples using matlab. Evaluation study results showed that: the model evaluation results are basically consistent with the actual situation, this model is suitable for the evaluation of automotive service. Proved that the comprehensive evaluation of BP neural network have speed computation, high efficiency, strong self-learning and wide adaptability.
\end{abstract}

KEYWORD: Automotive Service; Customer Satisfaction; BP Neural Network

\section{INTRODUCTION}

The idea of customer satisfaction originated in Europe, and American scholars cardozo reference it into commercial sector in 1965. Since 1977, the American scholar Hunt[1], Oliver[2] have been published many articles on customer satisfaction problem. Paolo Gaiardelli et[3] analyse from the point of service chain that it include component manufacturers, vehicle manufacturers, customers and assistance centers. Yu guoxin[4],[5] established a multi-level car service supply chain performance evaluation model based the core of service provider. Pei Cunqiang[6] 2008 drawed on The balanced scorecard, applied of the theory of customer satisfaction, service management, supply chain management theory comprehensively, constructed a comprehensive auto service performance evaluation system.

In summary, it can be seen that the research of automotive supply chain, car saled service and customer satisfaction measurement has been very mature, but few studies involve in customer satisfaction, and has not yet put forward automotive service satisfaction evaluation model for China's current stage. So, the researched BP neural network based saled service satisfaction in this paper have some theoretical significance and practical value to the automotive supply chain performance evaluation.

\section{THE EVALUATION MODEL BASED ON BP NEURAL NETWORK}

\subsection{BP Neural Network}

The neural network is simplification and simulation of biological neural network, It consists of input layer, hidden layer and output layer. There is no coupling between network nodes of same layer and layers take a fully connected. The output of inside neural each layer are transferred to the next layer, to achieve enhanced, reduced or inhibit these outbut by the coupling weights. Figure 1 shows a basic BP neurons, it has $\mathrm{n}$ inputs, each input is connected to the neuron node by a appropriate weight value wi, $\mathrm{i}=1,2, \ldots \mathrm{n}$.

The output function is: $y=f(W \times X, \theta), a=\sum_{i=1}^{n_{0}} w_{i} x_{i}$

$\mathrm{a}$ is the input of activation function. Another input of activation function is threshold of neurons.

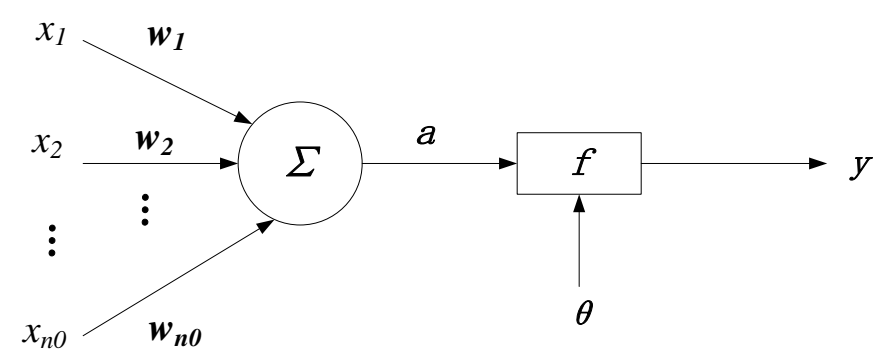

Fig.1 single neural model of BP Neural Network 
BP network can be seen as a highly nonlinear mapping from input to output, ie, $F: R^{n} \rightarrow R^{m}$, $f(X)=Y$. For sample collection, input $x_{i}\left(\in R^{n}\right)$ and output $g\left(x_{i}\right)=y_{i}$, may think there is a mapping $\mathrm{g}$ for $g\left(x_{i}\right)=y_{i}, \mathrm{i}=1,2 \ldots \mathrm{n}$. The neural network does several complex by simple nonlinear function and can be approximated by a complex function, then, get the best approximation of $\mathrm{f}$ is $\mathrm{g}$. The structure of BP network is showen as Figure 2.

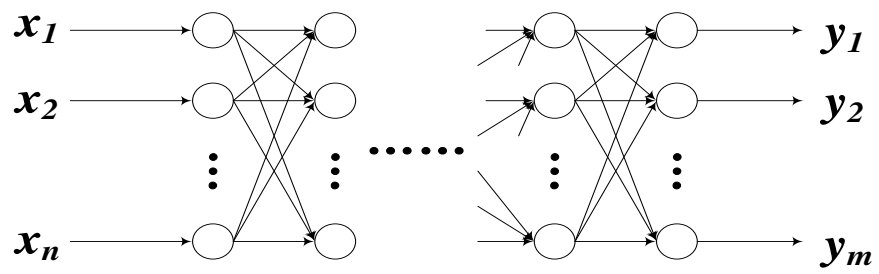

Fig.2 The structure of BP Neural Network

Studies have shown that, if given any $\varepsilon>0$ and any $\mathrm{L}_{2}$ function $f:[0,1]^{n} \rightarrow R^{m}$. there is a threelayer BP network, it can approximate $\mathrm{f}$ in an arbitrary precision squared error (BP Theorem). Although the BP theorem shows that as long as the BP network of three layers can be used to realize the L2 function, but in fact if you use three networks often requires a lot of hidden nodes, and the use of multi-layer network can reduce the number of nodes in hidden layer.

\subsection{The Mathematical Description of BP Neural Network}

The structure of multilayer feedforward networks based on BP algorithm is showed in Figure 3. This network has not only an input node, an output node, but also one or more hidden nodes. For input information, spread forward to the nodes of hidden layer, operate by Sigmoid type active function of each unit, spread output information of hidden node to output node and give results. The network learning process include forward and backward two parts, minimum the error signal through repeated use of the process. When the error achieve demand, learning process end.

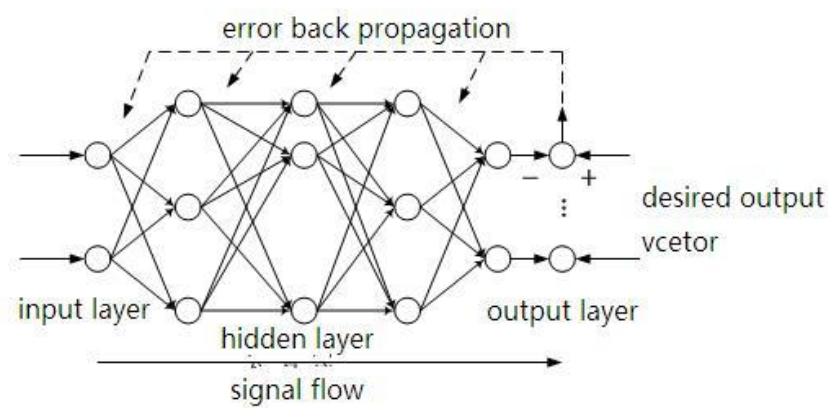

Fig. 3 the neural network structure based BP agorithm
Suppose any network has $\mathrm{L}$ layers and $\mathrm{n}$ nodes. If give $\mathrm{N}$ samples $\left(\mathrm{x}_{\mathrm{k}}, \mathrm{y}_{\mathrm{k}}\right)(\mathrm{k}=1-\mathrm{N})$, the output of either node $\mathrm{i}$ is $\mathrm{O}_{\mathrm{i}}$, the output is $\mathrm{y}_{\mathrm{k}}$ of input $\mathrm{x}_{\mathrm{k}}$, the output of node $\mathrm{i}$ is $\mathrm{O}_{\mathrm{ik}}$. In the I layer $\mathrm{j}$ unit of network, if input $\mathrm{k}$-th sample, the input of node $\mathrm{j}$ is:

$$
n e t_{j k}^{l}=\sum_{j} w_{i j}^{l} O_{j k}^{l-1}
$$

$O_{j k}^{l-1}$ represent layer 1-1, the output of node is:

$$
O_{j k}^{l}=f\left(n e t_{j k}^{l}\right)
$$

$f(x)$ is the active function of node $j$, use squared error function:

$$
E_{k}=\frac{1}{2} \sum_{i}\left(y_{j k}-\dot{y}_{j k}\right)^{2}
$$

$y_{j k}, \dot{y}_{j k}$ are the expect and real output of uint $\mathrm{j}$. the total error is:

$$
E=\frac{1}{2 N} \sum_{k=1}^{N} E_{k}
$$

$\mathrm{N}$ is the number of neural about output layer, $\delta_{j k}^{l}=\frac{\partial E_{k}}{\partial n e t_{j k}^{l}}$ then:

$\frac{\partial E_{k}}{\partial w_{i j}^{l}}=\frac{\partial E_{k}}{\partial n e t_{j k}^{l}} \frac{\partial n e t_{j k}^{l}}{\partial w_{i j}^{l}}=\frac{\partial E_{k}}{\partial n e t_{j k}^{l}} O_{j k}^{l-1}$

Node j is output uint, then $O_{j k}^{l}=\dot{y}_{j k}$,

$\delta_{j k}^{l}=\frac{\partial E_{k}}{\partial n e t_{j k}^{k}}=\frac{\partial E_{k}}{\partial \dot{y}_{j k}} \frac{\partial \dot{y}_{j k}}{\partial n e t_{j k}^{k}}=-\left(y_{k}-\dot{y}_{k}\right) f^{\prime}\left(n e t_{j k}^{l}\right)$

$\mathrm{J}$ is not output uint, then:

$\delta_{j k}^{l}=\frac{\partial E_{k}}{\partial n e t_{j k}^{k}}=\frac{\partial E_{k}}{\partial O_{j k}^{l}} \frac{\partial O_{j k}^{l}}{\partial n e t_{j k}^{k}}=\frac{\partial E_{k}}{\partial O_{j k}^{l}} f^{\prime}\left(n e t_{j k}^{l}\right)$

$O_{j k}^{l}$ is the input of next layer $(1+1)$, calculate $\frac{\partial E_{k}}{\partial O_{j k}^{l}}$, then:

$\frac{\partial E_{k}}{\partial O_{j k}^{l}}=\sum_{m} \frac{\partial E_{k}}{\partial n e t_{j k}^{l}} \frac{\partial n e t_{j k}^{l}}{\partial O_{j k}^{l}}=\sum_{m} \frac{\partial E_{k}}{\partial n e t_{j k}^{l+1}} w_{m j}^{l+1}=\sum_{m} \delta_{m k}^{l+1} w_{m j}^{l+1}$

Obtained from (7) and (8):

$\delta_{j k}^{l}=\sum_{m} \delta_{m k}^{l+1} w_{m j}^{l+1} f^{\prime}\left(n e t_{j k}^{l}\right)$

The steps of this back-propagation algorithm can be summarized as follows:

(1) Selected initial weights;

(2) The following procedure is repeated until convergence;

(1)For $\mathrm{k}=1-\mathrm{N}$ 
Forward process:calculate $O_{j k}^{l-1}, n e t_{j k}^{l}$ and $\dot{y}_{k}$ of each layer each uint, $\mathrm{k}=2-\mathrm{N}$

Backward process: for each layer(l=L-1 to 2), calculate $\delta_{j k}^{l}$

\section{(2)Correction weights}

$w_{i j}=w_{i j}-\mu \frac{\partial E}{\partial w_{i j}} ; \mu>0$

$\mu$ is step size, where $\frac{\partial E}{\partial w_{i j}}=\sum_{k=1}^{N} \frac{\partial E_{k}}{\partial w_{i j}}$

\section{CASE STUDY}

According to car saled customer satisfaction index(CSI) in the 2013 fourth quarter of one car brand, using the BP neural network established, evaluate the 14 service stations of this brand in a region.

Table 1 shows after-sale service satisfaction index of 12 car brand service stations in 2013 fourth quarter which are selected randomly nationwide. The after-sale service satisfaction take seven measure indicators, the overall evaluation, preparing and maintenance, reception staff, environmental facilities, the process of taking car, repair and maintenance quality, tracking service, they are represented by the letters a-g in table 1 .

Table 2 shows after-sale service satisfaction index score of 14 this car brand service stations in 2013 fourth quarter. The total score is 1000 points and the higher scores indicate higher customer satisfaction with car services.

According to part of the sample data in table 1, train the BP neural network, evaluate the 14 service stations in table 2 by established BP neural network evaluation model.

(1) Data normalization

Process the data between $[-1,1]$,transfer the score into a percentage number.

Table 1 after-sale service satisfaction index

\begin{tabular}{|c|c|c|c|c|c|c|c|c|}
\hline & $\mathrm{a}$ & $\mathrm{b}$ & $\mathrm{c}$ & $\mathrm{d}$ & $\mathrm{e}$ & $\mathrm{f}$ & $\mathrm{g}$ & $\mathrm{CSI}$ \\
\hline 1 & 935 & 949 & 956 & 934 & 923 & 944 & 930 & 940 \\
\hline 2 & 955 & 962 & 961 & 948 & 943 & 956 & 962 & 955 \\
\hline 3 & 936 & 944 & 954 & 945 & 924 & 943 & 938 & 941 \\
\hline 4 & 961 & 974 & 988 & 969 & 968 & 980 & 954 & 974 \\
\hline 5 & 907 & 927 & 943 & 829 & 876 & 923 & 904 & 903 \\
\hline 6 & 911 & 909 & 947 & 887 & 912 & 935 & 938 & 923 \\
\hline 7 & 897 & 947 & 959 & 891 & 903 & 922 & 891 & 920 \\
\hline 8 & 906 & 922 & 939 & 924 & 895 & 933 & 878 & 919 \\
\hline 9 & 935 & 939 & 944 & 910 & 920 & 931 & 906 & 927 \\
\hline 10 & 881 & 919 & 928 & 875 & 883 & 925 & 906 & 909 \\
\hline 11 & 956 & 960 & 966 & 975 & 931 & 956 & 943 & 955 \\
\hline 12 & 977 & 976 & 982 & 952 & 952 & 966 & 967 & 965 \\
\hline
\end{tabular}

Table 2 the score of after-sale service satisfaction index

\begin{tabular}{|c|c|c|c|c|c|c|c|}
\hline & $\mathrm{a}$ & $\mathrm{b}$ & $\mathrm{c}$ & $\mathrm{d}$ & $\mathrm{e}$ & $\mathrm{f}$ & $\mathrm{g}$ \\
\hline 1 & 927 & 935 & 946 & 945 & 913 & 937 & 943 \\
\hline 2 & 953 & 980 & 971 & 968 & 925 & 949 & 943 \\
\hline 3 & 924 & 952 & 950 & 951 & 915 & 933 & 895 \\
\hline 4 & 982 & 984 & 989 & 989 & 965 & 986 & 987 \\
\hline 5 & 860 & 911 & 900 & 847 & 852 & 895 & 778 \\
\hline 6 & 902 & 958 & 936 & 942 & 897 & 927 & 896 \\
\hline 7 & 993 & 998 & 992 & 989 & 990 & 992 & 988 \\
\hline 8 & 922 & 947 & 975 & 924 & 950 & 958 & 919 \\
\hline 9 & 935 & 957 & 961 & 975 & 929 & 938 & 911 \\
\hline 10 & 859 & 882 & 903 & 914 & 846 & 878 & 820 \\
\hline 11 & 962 & 969 & 977 & 973 & 939 & 952 & 928 \\
\hline 12 & 960 & 957 & 972 & 967 & 931 & 952 & 927 \\
\hline 13 & 929 & 952 & 950 & 924 & 940 & 943 & 920 \\
\hline 14 & 986 & 990 & 991 & 984 & 985 & 990 & 985 \\
\hline
\end{tabular}

(2) Network design

(1) Set the input and output nodes. Take 7 index values of sample as input vector of input node, take the satisfaction value as the expectation of the network output node.

(2) Compare and choose the number of hidden nodes. Establish BP neural network evaluation model of 7 input nodes, 17 hidden nodes and 1 output node.

(3) Select the transfer function. Select tansig function as the transfer function of the hidden layer neuron, select purelin function as transfer function of the output layer neuron.

(4) Select the training function. Consider the convergence speed and training precision, by comparison and testing, choose the LevenbergMarquardt algorithm to train the model network, the training function is trainlm.

(3) Anti-normalization.

Convert the network output into numerical scores.

\section{TRAINNING RESULTS}

Use the following statement, doing multiple network training in matlab tool. The process of network training is shown in Fig. 4.

net=newff(minmax $(\mathrm{P}),[17,1],\{$ 'tansig','purelin' $\}$,'tr ainlm');

net.trainParam.epochs $=1000$;

net.trainParam.lr $=0.001$;

net.trainParam.goal $=1 \mathrm{e}-10$;

$[$ net, $\operatorname{tr}]=\operatorname{train}($ net $, \mathrm{P}, \mathrm{T})$; 


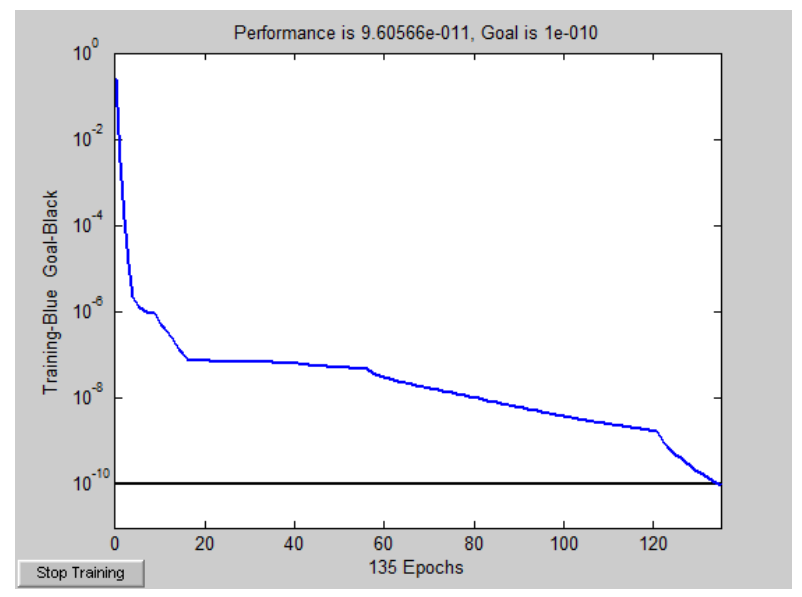

Fig. 4 The process of network training

RAINLM, Epoch 0/1000, MSE 3.74511/1e-010, Gradient 289.368/1e-010

TRAINLM, Epoch 25/1000, MSE 2.67629e007/1e-010, Gradient 0.000288916/1e-010

TRAINLM, Epoch 50/1000, MSE 8.10641e008/1e-010, Gradient 0.000745514/1e-010

TRAINLM, Epoch 75/1000, MSE 4.67815e008/1e-010, Gradient 0.000717933/1e-010

TRAINLM, Epoch 100/1000, MSE 1.13976e008/1e-010, Gradient 0.000128943/1e-010

TRAINLM, Epoch 125/1000, MSE 3.82084e009/1e-010, Gradient 0.000107533/1e-010
TRAINLM, Epoch 150/1000, MSE 2.20368e009/1e-010, Gradient 0.000610212/1e-010

TRAINLM, Epoch 175/1000, MSE 1.33049e010/1e-010, Gradient 2.86924e-005/1e-010

TRAINLM, Epoch 181/1000, MSE 9.83276e011/1e-010, Gradient 1.62932e-005/1e-010

TRAINLM, Performance goal met.

The setting target is 1e-010, after running the program, the approximation error curve is shown in Figure 4. We can see from it, after iterating of 135 times and the error value has less than the target. Then, the iteration is terminated, the system display "Performance goal met", the error of network training is down to the target and the network stop training. All indicate the rate of convergence is faster.

\section{EVALUATION RESULTS AND ANALYSIS}

After the network training, normalize the data in Figure 2 samely and input the model, Then, take inverse normalization. Compare the obtained results with the original evaluation results as shown in Figure 3 , it consistent with the original. So, It can reflect the ranking of service performance about the service station in service area, the model can be used for evaluation of car service performance.

Fig. 3 the comparison of evaluation results

\begin{tabular}{|c|c|c|c|c|c|c|c|c|c|c|c|c|c|c|}
\hline & 1 & 2 & 3 & 4 & 5 & 6 & 7 & 8 & 9 & 10 & 11 & 12 & 13 & 14 \\
\hline BP-CSI & 935 & 953 & 933 & 983 & 883 & 933 & 990 & 950 & 943 & 886 & 955 & 952 & 941 & 988 \\
\hline CSI & 935 & 954 & 933 & 983 & 872 & 926 & 992 & 949 & 944 & 875 & 956 & 951 & 940 & 988 \\
\hline
\end{tabular}

\section{CONCLUSION}

This paper established a car saled service evaluation model based on BP neural network, detailed the model structure, algorithm theory and algorithm steps. For car saled service satisfaction index of one brand, using the model evaluate the after-sales service satisfaction in the fourth quarter 2013 about 14 service stations in a region. Analyze the evaluation results and The result show that: the evaluation results of the model is basically the same situation, this model is suitable for the evaluation of automotive service performance.

\section{REFERENCES}

[1] Hunt, H.K..Overview and Future Research Directions. Conceptualization and Measurement Satisfaction and Dissatisfaction. MA: Marketing Science Institute, 1977.
[2] Oliver, Richard L. Measurement and Evaluation of Satisfaction Process Retailing Setting. Journal of Retailing, 1981.

[3] Paolo Gaiardelli, Nicola Saccani, Lucrezia Songini. Performance measurement of the after-sales service network-Evidence from the automotive industry. Computers in Industry 58(2007): 698-708

[4] Yu. Guo Xin, Multi-level automotive service performance evaluation model. Applied Mechanics and Materials, v 477-478, p 1517-1520, 2014.

[5] R. Cooper and R. Slagmulder, Supply Chain Development for the Lean Enterprise: Interorganisational Cost Management, Productivity Press, Portland (1999).

[6] L.M. Ellram, Total cost of ownership. An analysis approach for purchasing, International Journal of Physical Distribution and Logistics Management 25 (8) (1995), pp. 4-23. 